\title{
COMPOSIÇÃO QUÍMICA DA CARNE DE CABRITOS ABATIDOS EM IDADES DIFERENTES ${ }^{1}$
}

\section{CHEMICAL COMPOSITION OF MEAT FROM KIDS SLAUGHTERED AT DIFFERENT AGES}

\author{
Kessler, J.D..$^{*}$; Osório, M.T.M. ${ }^{3}$; Nörnberg, J.L.2; Osório, J.C.S. ${ }^{3}$; Esteves, R.M.G. ${ }^{1 ;}$ Souza, \\ A.P.B. ${ }^{2}$; Arnoni, R.K. ${ }^{1}$; Borba, M.S. ${ }^{4}$; Oliveira, R.M. ${ }^{1}$ e Ferreira, O.G.L. ${ }^{1}$
}

\begin{abstract}
1'Departamento de Zootecnia. Universidade Federal de Pelotas. Pelotas, RS. Brasil. *jdkessler@gmail.com ${ }^{2}$ Departamento de Tecnologia e Ciências de Alimentos. UFSM. Santa Maria, RS. Brasil.

${ }^{3}$ Universidade Federal da Grande Dourados. Dourados, MS. Brasil.

${ }^{4}$ Empresa Brasileira de Pesquisa Agropecuária. Embrapa Pecuária Sul. Bagé, RS. Brasil.
\end{abstract}

\section{PaLAVRAS CHAVE ADICIONAIS}

Carcaça. Colesterol. Lipídios. Umidade.

\section{RESUMO}

O objetivo deste trabalho foi avaliar a composição química da carne de três regiões da carcaça de cabritos naturalizados e abatidos, criados em sistema extensivo na Região do Alto Camaquã. Foram utilizados 15 animais por tratamento, com 8-9 e 11-12 meses de idade. Foi determinada a composição centesimal (umidade, proteína, matéria mineral, lipídios e colesterol) da paleta, lombo e perna. Cabritos abatidos mais jovens apresentam maior concentração de umidade e matéria mineral no lombo, paleta e perna $(p<0,05)$. Já os teores de gordura foram superiores nos cabritos abatidos mais velhos $(p<0,05)$. Para o colesterol, somente na perna de cabritos abatidos mais jovens foram inferiores as demais regiões $(p<0,05)$. Não houve diferença em relação ao colesterol total para cabritos mais velhos $(p>0,05)$ nas diferentes regiões da carcaça. Com o avanço da idade de abate dos cabritos eleva-se o teor de proteína e de gordura, porém o colesterol não se modifica ao longo do tempo. As regiões da carcaça apresentaram distinta composição química. Desta forma, ressalta-se que em sistema extensivo de criação os animais abatidos com 11 a 12 meses apresentam teores nutricionais mais elevado na sua carne. Por tanto, nessas condições recomenda-se abater animais com idade entre 11 a 12 meses.

${ }^{1}$ Projeto financiado pelo $\mathrm{CNPq}(475903 / 2010-2)$. Parte da Tese de doutorado do primeiro autor.

\section{AdDitional KEYWORDS}

Carcass. Cholesterol. Lipids. Moisture.

\section{SUMMARY}

The objective of this study was to evaluate the chemical composition of meat from three portions of the carcass of kids raised in range conditions and slaughtered at 8-9 or 11-12 months old. The trial was conducted in the region of Alto Camaquã and had 15 animals per group. Chemical composition of the carcass (moisture, protein, ashes, fats, and cholesterol) was determined from the shoulder, loin, and legs. Kids slaughtered younger had higher moisture and ash content in all three portions $(p<0.05)$ when compared to older animals. Fat levels only were higher in kids slaughtered at an older age $(p<0.05)$. Cholesterol content only on the leg, was lesser than the two other portions in younger animals $(p<0.05)$. There were no differences observed between the three portions on the older animals. Older kids at slaughter had higher content of protein and fat but cholesterol remained unchanged. The three portions of the carcass had distinct chemical composition. Our results suggest that in range conditions the slaughter of animals should occur at 11-12 months old, resulting in meat with higher nutritional content in all portions of the carcass.

\section{INTRODUÇÃO}

O ecossistema que abrange a região do Alto Camaquã, no sul do Brasil, com aproximadamente $8300 \mathrm{~km}^{2}$ de área, conserva características edafoclimáticas que ao longo 
do tempo tem sido utilizadas para produção de uma caprinocultura sustentável, com base nos recursos locais disponíveis para a diferenciação da carne de animais naturalizados, (Oliveira et al., 2012). Segundo os mesmo autores, os caprinos dessa região são naturalizados, sem raça definida (SRD) e criados em condições extensivas, tendo como base alimentar os recursos ecossistêmicos locais, incluindo o estrato herbáceo, arbóreo e arbustivo. Tais características podem constituir-se em elementos para diferenciação da carne de cabrito do Alto Camaquã.

A vegetação da região é formada, em grande parte, por espécies arbustivoarbóreas associadas ao campo (GirardiDeiro, 2002). De acordo com Boldrini (2009) a vegetação savanóide da região, assentase sobre solos rasos, muito pedregosos, procedentes de granito, com um relevo ondulado.

A qualidade da carne pode ser afetada por diversos fatores como a raça, a idade de abate, sistema de alimentação, assim como o sexo (Sañudo et al., 1997). Jardim et al. (2007) observaram modificações na composição química da carne de animais abatidos com idades diferentes. Além disso, Berg e Butterfield (1976) ressaltam que os principais componentes químicos do organismo animal são água, gordura, proteína e minerais.

Conforme Silva Sobrinho et al. (2008), a qualidade da carne sofre alterações consideráveis com a idade, decorrente de mudanças na composição e nas características metabólicas dos músculos. Para Todaro et al. (2002) o aumento da idade de abate contribui para a deposição de gordura e também de músculo na carcaça. Conforme estes autores, a gordura aumenta com a idade de abate, assim como, o crescimento de músculo e osso.

A crescente demanda por alimento de qualidade tem sido a principal forma de buscar a melhoria dos produtos comercializados de origem animal, nesse o sistema de criação tem um papel fundamental. Uma vez que, há necessidade de se atribuir um conceito universal sobre qualidade nos produtos. Não obstante, as pesquisas sobre a composição química da carne vermelha têm relacionado aos diversos aspectos à saúde humana.

Nos últimos anos há um crescente interesse pela carne caprina, principalmente de animais jovens, em função de suas propriedades nutricionais, pois apresentam baixos teores de colesterol, gordura saturada e calorias, além de elevados níveis de proteína (Madruga, 1999). Um dos pontos fundamentales é a composição química da carne a qual varia em função da idade e entre as diferentes regiões da carcaça (Zeola et al., 2004).

O objetivo deste trabalho foi avaliar a composição química da carne em três regiões da carcaça de cabritos abatidos em idades diferentes e criados em sistema extensivo na Região do Alto Camaquã.

\section{MATERIAL E MÉTODOS}

A pesquisa foi conduzida no $2^{\circ}$ Subdistrito das Palmas/Bagé-RS, localizado dentro da área geográfica do Território do Alto Camaquã (3058' 44.7" S; 53ํ42’ 28,7" O), entre os anos de 2008 e 2009. O sistema de criação desenvolvido é o extensivo com caprinos cruza Angorá, com pastoreio combinado entre bovinos e ovinos e alimentação exclusiva de pastagem nativa e do estrato arbóreo-arbustivo da região.

No período entre o jejum e o abate cada animal foi pesado e avaliado quanto à condição corporal (escala subjetiva de 1 a 5, com escala de 0,5 , em que $1=$ excessivamente magra e 5= excessivamente gorda) conforme Osório e Osório (2005). Foi estabelecido como parâmetro para abate a condição corporal de 3,0 a 3,5, com o objetivo de uniformização e foco no produtor (Osório et al., 2012).

Os cabritos foram abatidos de acordo com os procedimentos que caracterizam o 


\section{COMPOSIÇÃO DA CARNE DE CABRITOS ABATIDOS EM IDADES DIFERENTES}

abate humanitário (Monteiro Júnior, 2000). As carcaças foram acondicionadas em uma câmera fria com temperatura de $1^{\circ} \mathrm{C}$ por um período de $18 \mathrm{~h}$, para que ocorresse o processo de modificações bioquímicas ( $r$ gor mortis) necessárias para a transformação de músculo em carne. Após as carcaças foram divididas em duas meias carcaças, sendo retirado da meia carcaça esquerda os músculos Longissimus região 1 (lombo), Triceps brachii (TB) e Infraspinatus (IS) região 2 (paleta) e Biceps femoris (BF) região 3 (perna), para determinação da composição centesimal. As amostras foram embaladas em sacos plásticos, identificadas e armazenadas em freezer $\left(-18^{\circ} \mathrm{C}\right)$, sendo mantidas nesta temperatura até a realização das análises.

Uma fatia dos músculos foi descongelada a $4{ }^{\circ} \mathrm{C}$ para a realização da toalete, com a retirada da gordura subcutânea e a fascia para análise somente da porção interna dos mesmos. Após foi utilizado um microprocessador para trituração da carne e um equipamento turrax para homogeneização, obtendo assim uma pasta. Sendo feitas as seguintes determinações: teor de umidade, matéria mineral $(\mathrm{MM})$, proteína, lipídios totais (LT) e colesterol total.

Para determinação da umidade as amostras foram pesadas in natura e colocadas em uma estufa de circulação de ar forçada $\left(55^{\circ} \mathrm{C}\right)$, retiradas somente quando o peso permanecesse constante (72 horas). Após as amostras foram moídas em moinho tipo Wiley, utilizando peneira com malha de 1 mm. Neste material, foram efetuadas as seguintes determinações: matéria seca(MS) a $105^{\circ} \mathrm{C}$ por 16 horas, para determinação da umidade, matéria mineral (MM) por incineração a $550{ }^{\circ} \mathrm{C}$ (durante 5 horas), nitrogênio, pelo método de Kjeldahl, utilizando-se o fator de 6,25 para conversão de nitrogênio total em proteína. Todos os constituintes foram determinados segundo metodologia descrita pela AOAC (2000). Para a determinação de lipídios totais (LT) foram utilizadas amostras in natura, sendo a metodologia empregada de acordo com Bligh e Dyer (1959).

Para a determinação do colesterol foi realizado a saponificação direta das amostras, para quantificação do colesterol através da metodologia enzimática (Nogueira e Bragagnolo, 2002). Os resultados foram expressos em miligramas de colesterol por $100 \mathrm{~g}$ de carne.

O delineamento experimental usado foi o inteiramente casualizado com arranjo fatorial 2 × 3 (duas idades e três regiões da carcaça), totalizando 15 animais por tratamento. Foi realizada a análise de variância pelo procedimento GLM do pacote estatístico (SAS, 2001) e as médias comparadas pelo teste de Tukey a $5 \%$ de significância de erro. O modelo matemático usado foi:

$$
\tilde{\mathrm{a}}_{\mathrm{ijk}}=\mu+\mathrm{I}_{\mathrm{i}}+\mathrm{R}_{\mathrm{j}}+\mathrm{IR}_{\mathrm{ij}}+\stackrel{\circ}{\mathrm{ijk}}_{\mathrm{i}}
$$

sendo:

$\tilde{\mathrm{a}}_{\mathrm{ijk}}=$ representa as variáveis dependentes;

$\mu=$ média geral de todas as observações;

$\mathrm{I}_{\mathrm{i}}=$ efeito do $i$-ésimo da idade;

$\mathrm{R}_{\mathrm{i}}=$ efeito do $j$-ésimo da região da carcaça;

$\mathrm{IR}_{\mathrm{ij}}=$ efeito da interação entre a idade e a região da carcaça;

$\mathrm{a}_{\mathrm{ijk}}=$ erro aleatório residual.

\section{RESULTADOSEDISCUSSÃO}

O teor de umidade das regiões do lombo, paleta e perna foram superiores $(\mathrm{p}<0,05)$ nos animais mais jovens ( $8-9$ meses de idade) em relação aos abatidos com 11-12 meses de idade (tabelas I, II e III). Isso se deve a curva de crescimento dos animais referente ao tipo de tecido. Premissa essa que corrobora com Berg e Butterfield (1976), Madruga et al.(2000) e Beserra et al. (2001) a maturidade é refletida por aumento na proporção de gordura e decréscimos na proporção de água, proteína e minerais no corpo.

Berg e Butterfield (1976), Di Marco (1994) e Verde (1996) relataram o mesmo padrão de desenvolvimento, embora com outras espécies animais. Segundo os autores, animais mais jovens apresentam maior 
Tabela I. Médias (\%) e desvios-padrão da composição do músculo Longissimus de cabritos. (Means (\%) and standard deviations of the chemical composition of the Longissimus muscle of kids).

\begin{tabular}{|c|c|c|c|c|c|}
\hline & Idade & eses) & & & \\
\hline & $8-9$ & $11-12$ & Média & CV\% & $p>F$ \\
\hline Umidade & $75,99 \pm 1,13$ & $74,78 \pm 1,59$ & $75,20 \pm 1,55$ & 1,93 & 0,0254 \\
\hline Proteína & $20,20 \pm 0,74$ & $20,19 \pm 0,94$ & $20,20 \pm 0,86$ & 4,33 & 0,9730 \\
\hline Matéria mineral & $1,25 \pm 0,13$ & $1,13 \pm 0,10$ & $1,17 \pm 0,12$ & 9,66 & 0,0063 \\
\hline Lipídios totais & $0,57 \pm 0,16$ & $1,03 \pm 0,37$ & $0,82 \pm 0,37$ & 35,92 & 0,0004 \\
\hline Colesterol total & $76,27 \pm 4,47$ & $73,33 \pm 5,41$ & $74,76 \pm 5,12$ & 6,66 & 0,0993 \\
\hline
\end{tabular}

teor de água e menor em gordura. Além de que, as concentrações de água, proteína e minerais decrescem com a idade e com a engorda. Entretanto, Madruga et al. (2002) observaram aumento do teor de proteína no músculo de cabritos mais velhos. Perez et al. (2002) compararam animais sacrificados com diferentes pesos $(15,25,35$ e $45 \mathrm{~kg})$, obtiveram variação de 76,9 a $72,9 \mathrm{~g} / 100 \mathrm{~g}$ de umidade. Ratifica-se que com o crescimento ao longo do tempo, há diminuição nos teores de umidade nos animais sacrificados mais velhos, ou seja, com maiores pesos.

Não houve diferença $(p>0,05)$ entre as idades sobre o teor de proteína do lombo (tabela I), entretanto, para paleta e perna, tabelas II e III, respectivamente, os teores foram superiores $(\mathrm{p}<0,05)$ nos animais abatidos mais velhos em relação aos mais jovens. Fato esse explicado devido a hipertrofia muscular destes animais criados em siste- mas extensivo, atribuído ao desenvolvimento dos membros e peso destes em relação aos animais mais jovens. Além disso, Lawrie (1961) já havia observado que independente da espécie, raça ou sexo, a composição dos músculos varia com o aumento da idade do animal, havendo aumento geral em vários parâmetros com exceção da água. O mesmo autor relatou que a taxa de incremento não é idêntica em todos os músculos. Essa premissa mais tarde foi confirmada por Berg e Butterfield (1976).

Para lipídios totais do lombo e da perna os teores foram superiores para os animais mais velhos $(p<0,05)$ em relação aos mais jovens (tabelas I e III). Entretanto, não houve diferença $(p>0,05)$ entre as idades de abate para paleta (tabela II). Mahgob et al. (2004) verificaram que com o aumento do nível nutricional em cordeiros ocorre aumento dos teores de gordura e diminuição da

Tabela II. Médias (\%) e desvios-padrão da composição dos músculos Triceps brachii $e$ Infraspinatus de cabritos. (Means (\%) and standard deviations of the composition of the Triceps brachii and Infraspinatus muscles in kids).

\begin{tabular}{lccccr}
\hline \multicolumn{2}{c}{ Idades (meses) } & & & \\
& $8-9$ & $11-12$ & Média & CV\% & $p>F$ \\
\hline Umidade & $77,19 \pm 0,91$ & $76,32 \pm 0,52$ & $76,63 \pm 1,13$ & 0,89 & 0,0012 \\
Proteína & $18,05 \pm 0,85$ & $19,34 \pm 0,61$ & $18,88 \pm 0,74$ & 3,72 & $<0,0001$ \\
Matéria mineral & $1,31 \pm 0,17$ & $1,11 \pm 0,06$ & $1,18 \pm 0,13$ & 9,68 & $<0,0001$ \\
Lipídios totais & $0,74 \pm 0,13$ & $0,65 \pm 0,14$ & $0,69 \pm 0,16$ & 19,24 & 0,6938 \\
Colesterol total & $77,86 \pm 4,71$ & $77,37 \pm 5,29$ & $77,62 \pm 4,92$ & 6,46 & 0,7970 \\
\hline
\end{tabular}

Archivos de zootecnia vol. 63, núm. 241, p. 156. 
COMPOSIÇÃO DA CARNE DE CABRITOS ABATIDOS EM IDADES DIFERENTES

Tabela III. Médias (\%) e desvios-padrão da composição do músculo Biceps femoris de cabritos. (Means (\%) and standard deviations of the composition of the Biceps femoris muscle of kids).

\begin{tabular}{lccccr}
\hline & \multicolumn{2}{c}{ Idades (meses) } & & & \\
& $8-9$ & $11-12$ & Média & CV\% & $\mathrm{p}>\mathrm{F}$ \\
\hline Umidade & $77,51 \pm 0,81$ & $75,76 \pm 0,88$ & $76,36 \pm 1,59$ & 1,13 & $<0,0001$ \\
Proteína & $18,53 \pm 0,98$ & $19,96 \pm 0,49$ & $19,47 \pm 0,94$ & 3,96 & $<0,0001$ \\
Matéria mineral & $1,41 \pm 0,17$ & $1,25 \pm 0,10$ & $1,30 \pm 0,10$ & 10,27 & 0,0016 \\
Lipídios totais & $0,51 \pm 0,11$ & $0,72 \pm 0,17$ & $0,62 \pm 0,34$ & 24,13 & 0,0014 \\
Colesterol total & $71,72 \pm 5,34$ & $73,67 \pm 8,98$ & $72,86 \pm 7,63$ & 10,58 & 0,5071 \\
& & & & & \\
\hline
\end{tabular}

umidade no músculo. Já no presente estudo os animais foram criados em sistema extensivo, sendo os mesmo forçados a buscar seu alimento na vegetação e balanceá-los, desta forma, não há um aumento discrepante nos níveis nutricionais, principalmente relacionados com a energia da dieta, representada pelo amido da ração dos animais confinados ou mesmo em sistemas semiintensivo de criação. Segundo Lawrie (1985), relação inversa entre os teores de umidade e gordura, os quais afetam diretamente as características sensoriais de suculência das carnes em geral.

Os teores de matéria mineral do lombo, paleta e perna foram superiores $(\mathrm{p}<0,05)$ nos animais abatidos mais jovens (tabelas I, II e III). Resultado que corrobora com os encontrados por Madruga et al. (2000) e Beserra et al. (2001).

Em relação aos teores de colesterol total do lombo, paleta e perna não foi observado diferenças $(p>0,05)$ entre as idades de abate (tabelas I, II e III). Isso denota que há uma síntese de colesterol uniforme independente da idade de abate podendo ser diferenciada em regiões da carcaça ou mesmo de músculo para músculo.

De acordo com Huidobro (1992), os animais seguem um modelo de desenvolvimento disto-proximal em que as extremidades distais são mais precoces, pois apresenta maior proporção do seu peso maduro antes do restante do corpo. Essa premissa é confirmada quando se compara regiões distintas da carcaça, conforme resultados do presente estudo.

As curvas de crescimentos dos tecidos muscular e adiposo, em função do aumento do peso dos animais, apresentam padrões distintos. Os músculos têm crescimento mais acelerado em animais mais jovens. Enquanto, a gordura apresenta crescimento mais acentuado em animais com idade mais avançadas. Ao se analisar o desenvolvimento do animal, deve-se, portanto, considerar os aspectos de desenvolvimento dos tecidos em conjunto e as características de deposição de gordura nas diferentes partes do corpo (Lawrie, 1961; Sainz, 1996). Desta forma, foi observado teores mais elevados de umidade, mostrado no presente trabalho.

Ao comparar as regiões da carcaça, a umidade foi superior na paleta e perna $(\mathrm{p}<0,05)$ em relação ao lombo (tabela IV) para animais de 8-9 meses de idade (animais jovens). Entretanto, o teor de proteína foi superior no lombo $(\mathrm{p}<0,05)$ em relação as demais partes estudadas (tabela IV). Podese atribuir a isso a maior concentração de nitrogênio não-protéico em relação aos demais músculos estudados, conforme Lawrie (1961), atingindo maior valor entre 12 meses de idade. Além disso, Kamble et al. (1989) declararam que não existe praticamente nenhuma vantagem em se abater caprinos com idade inferior a 10 meses de idade, o que resultaria em um pequeno aumento no peso da carcaça e numa redução na percentagem de músculos. 
Tabela IV. Médias (\%) e desvios-padrão da composição das regiões da carcaça de cabritos. (Means (\%) and standard deviations of the chemical composition of the portions of the carcass of kids).

\begin{tabular}{|c|c|c|c|c|c|}
\hline & & 8-9 meses & & & \\
\hline & Lombo & Paleta & Perna & Média & $\mathrm{CV} \%$ \\
\hline Umidade & $75,99 \pm 1,13^{b}$ & $77,19 \pm 0,91^{a}$ & $77,51 \pm 0,81^{a}$ & $76,89 \pm 1,14$ & 1,25 \\
\hline Proteína & $20,20 \pm 0,74^{a}$ & $18,05 \pm 0,85^{b}$ & $18,53 \pm 0,98^{b}$ & $18,93 \pm 1,26$ & 4,55 \\
\hline Matéria mineral & $1,25 \pm 0,13$ & $1,31 \pm 0,17$ & $1,41 \pm 0,17$ & $1,32 \pm 0,17$ & 12,36 \\
\hline Lipídios totais & $0,57 \pm 0,16^{b}$ & $0,74 \pm 0,13^{\mathrm{a}}$ & $0,51 \pm 0,11^{\mathrm{b}}$ & $0,61 \pm 0,16$ & 21,99 \\
\hline Colesterol total & $76,28 \pm 4,47^{a}$ & $77,86 \pm 4,71^{a}$ & $71,72 \pm 5,34^{b}$ & $75,50 \pm 5,32$ & 6,37 \\
\hline
\end{tabular}

Médias seguidas por letras minúsculas diferentes, na mesma linha, diferem $(p<0,05)$ pelo teste de Tukey.

No presente estudo foi verificado que o abate de animais mais jovens apresenta vantagens em relação a composição química da carne e demonstra um maior ganho de peso, diminuindo o tempo para comercialização dos animais. Sendo assim, discordando dos autores supracitados que relacionam somente peso de carcaça e músculo como fator fundamental.

Já para o teor de matéria mineral os resultados não apresentaram diferenças $(\mathrm{p}>0,05)$ entre as regiões (tabela IV). Isso pode ser devido ao mesmo nível de deposição dos minerais nas diferentes regiões da carcaça neste período de desenvolvimento.

Em relação aos lipídios totais os valores encontrados na paleta foram superiores $(\mathrm{p}<0,05)$ ao lombo e perna (tabela IV). Isso pode ser explicado pela maior precocidade da paleta em relação as demais regiões.

O colesterol foi superior no lombo e paleta $(\mathrm{p}<0,05)$ em relação a perna (tabela IV). Fato este relacionado com a idade do animal, pois animais mais jovens apresentam menor teor de colesterol na carne (Madruga et al., 2002). Pode ser ressaltado que o colesterol é um componente de suma importância na estrutura de membra celular, devido atuar na estabilidade da mesma. Além do $\mathrm{pH}$ final da carne ter influência na capacidade de retenção de água, também podemos atribuir o mesmo com o teor de colesterol. Pelo fato supracitado anteriormente.

Paleta e perna apresentaram teores de umidade superior $(p<0,05)$ em relação ao

Tabela V. Médias (\%) e desvios-padrão da composição das regiões da carcaça de cabritos. (Means (\%) and standard deviations of the composition of the portions of the carcass of kids).

\begin{tabular}{lccccc}
\hline & \multicolumn{3}{c}{$11-12$ meses } & Ména & CV\% \\
\hline Umidade & Lombo & Paleta & Perna & (4, \\
Proteína & $74,78 \pm 1,59^{\mathrm{b}}$ & $76,32 \pm 0,52^{\mathrm{a}}$ & $75,76 \pm 0,88^{\mathrm{a}}$ & $75,61 \pm 1,26$ & 1,46 \\
Matéria mineral & $20,19 \pm 0,94^{\mathrm{a}}$ & $19,33 \pm 0,61^{\mathrm{b}}$ & $19,96 \pm 0,49^{\mathrm{a}}$ & $19,83 \pm 0,78$ & 3,55 \\
Lipídios totais & $1,13 \pm 0,10^{\mathrm{b}}$ & $1,11 \pm 0,06^{\mathrm{b}}$ & $1,25 \pm 0,10^{\mathrm{a}}$ & $1,16 \pm 0,11$ & 7,92 \\
Colesterol total & $1,03 \pm 0,37^{\mathrm{a}}$ & $0,65 \pm 0,14^{\mathrm{b}}$ & $0,72 \pm 0,17^{\mathrm{b}}$ & $0,80 \pm 0,29$ & 31,17 \\
& $73,33 \pm 5,41$ & $77,37 \pm 5,29$ & $73,67 \pm 8,98$ & $74,63 \pm 7,66$ & 9,20 \\
\hline
\end{tabular}

Médias seguidas por letras minúsculas diferentes, na mesma linha, diferem $(p<0,05)$ pelo teste de Tukey.

Archivos de zootecnia vol. 63, núm. 241, p. 158. 


\section{COMPOSIÇÃO DA CARNE DE CABRITOS ABATIDOS EM IDADES DIFERENTES}

lombo (tabela V). Isso pode ser explicado pelo maior teor de lipídios no lombo que nos demais músculos.

Enquanto para proteína tanto lombo como perna apresentaram maior teor $(p<0,05)$ que a paleta (tabela $\mathbf{V})$. O inverso pode-se observar em relação a matéria mineral, já que a perna apresentou valores maiores $(\mathrm{p}<0,05)$ que as demais partes (tabela V). Grande parte pode ser relacionados com a concentração de cálcio e ferro, principalmente este último, pela maior atividade desta musculatura em relação as demais estudadas, característicos de fibras vermelhas por apresentar maior concentração de citocromos e mioglobinas (Flores e Bermell, 1984). Madruga et al. (2002) relatam que com o aumento da idade de abate os teores de ferro são aumentados na composição química do músculo.

Os teores de lipídios totais do lombo foram superiores $(\mathrm{p}<0,05)$ as demais regiões (tabela V), fato este justificável pela utilização do músculo na vida do animal, os músculos do lombo são menos solicitados

\section{BIBLIOGRAFIA}

AOAC. Association of Official Analytical Chemists. 2000. Official Methods of Analysis. AOAC. Washington. 1018 pp.

Berg, R.T. and Butterfield, R.M. 1976. New concepts of cattle growth. Sydney University. New York. $240 \mathrm{pp}$.

Beserra, F.J.; Moura, R.P.; Da Silva, E.M.C. e Madruga, M.S. 2001. Características químicas e físico-químicas da carne de caprinos SRD com diferentes pesos de abate. Revista Tecnol Carnes, 3: 1-6.

Boldrini, I.I. 2009. A Flora dos Campos do Rio Grande do Sul. In: Pillar, V.R.D.P.; Müller, S.C. (Org.). Campos Sulinos: conservação e uso sustentável da diversidade. MMA. Brasília. pp. 65-79.

Bligh, E.G. and Dyer, W.J. 1959. A rapid method of total lipid extraction and purification. Can J Biochem Phisiol, 37: 911-917.

Di Marco, O.N. 1994. Crecimiento y respuesta quando comparado com os da perna (Madruga et al., 2005). Também pode ser justificado pela distribuição e a característica de deposição da gordura nos diferentes músculos, conforme relatado por Lawrie (1961).

Já para os teores de colesterol total as três regiões não apresentaram diferenças ( $p>0,05)$, mostrando padrão de deposição anteroposterior e que aos 11 a 12 meses de idade as concentrações são as mesmas, independente da região analisadas.

\section{CONCLUSÕES}

Com o avanço da idade de abate dos cabritos eleva-se o teor de proteína e de gordura, porém o colesterol não se modifica ao longo do tempo. As regiões da carcaça apresentaram distinta composição química. Desta forma, ressalta-se que em sistema extensivo de criação os animais abatidos com 11 a 12 meses apresentam teores nutricionais mais elevado na sua carne, o que acontece com as demais regiões da carcaça. Por tanto, nessas condições recomenda-se abater animais com idade entre 11 a 12 meses.

animal. Asociación Argentina de Producción Animal. Balcarce. 129 pp.

Flores, J. e Bermell, S. 1984. Propiedades funcionales de las proteínas miofibrilares: Capacidad de retención de agua. Agroquím Tecnol Alim, 24: 151-158.

Girardi-Deiro, A.M. 2002. Efeito do corte e queima de plantas lenhosas sobre um campo natural na Serra do Sudeste. Embrapa Pecuária Sul. Bagé, RS. Circular Técnica, 29.

Huidobro, F.R. 1992. Estudios sobre crecimiento y desarrollo en corderos de raza Manchega. 1992. 191 f. Tesis (Doctoral). Universidad Complutense. Facultad de Veterinária. Madrid.

Jardim, R.D.; Osório, J.C.S.; Osório, M.T.M.; Mendonça, G.; Esteves, R. e Gonçalves, M. 2007. Efeito da idade de abate e castração sobre a composição tecidual e química da paleta e da perna de ovinos corriedale. Rev Bras Agrociência, 13: 237-242. 
Kamble, V. J.; Bonde, H. S.; Kulkarni, K.D. and Kulkarni, D.N. 1989. Quality aspect of Osmanabadi goat meat. J Feed Sci Technol, 26: 99-101.

Lawrie, R.A. 1985. Meat Science. $4^{\text {th }}$ ed. Pergamon Press. Oxford. $267 \mathrm{pp}$.

Lawrie, R.A. 1961. Studies on muscles of meat animals. 1. Differences in composition of beef Longissimus dorsi muscle determined by age and anatomical position. J Agric Sci, 56: 56249.

Madruga, M.S. 1999. Artigo técnico: Carne caprina: Verdades e mitos à luz da ciência. Rev Nac Carne, 264: 34-40.

Madruga, M.S.; Arruda, S.G.B.; Narain, N. and Costa, R.G. 2000. Castration and slaughter age affects on panel assessment and aroma compounds of the mestiço goat meat. Meat Sci, 56: 117-125.

Madruga, M.S.; Narain, N.; Arruda, S.G.B.; Souza, J.G.; Costa, R.G. e Beserra, F.J. 2002. Influência da idade de abate e da castração nas qualidades físico-químicas, sensoriais e aromáticas da carne caprina. Rev Bras Zootecn, 31: 15621570.

Madruga, M.S.; Sousa, W.H.; Rosale, M.D.; Cunha, M.G.G. e Ramos, J.L.F. 2005. Qualidade da carne de cordeiros Santa Inês terminados com diferentes dietas. Rev Bras Zootecn, 34: 309315.

Mahgob, I.T.; Kadim, N.M.; Al Saquyr, R.M. and AIBusaidi, R.M. 2004. Effects of body weigth and sex on carcass tissue distribuition in goat. Meat Sci, 67: 577-585.

Monteiro Júnior, I.A. 2000. Avaliação das técnicas de insensibilização de ovinos abatidos na região de Botucatu. Dissertação (Mestrado em Medicina Veterinária). Faculdade de Medicina Veterinária e Zootecnia. Universidade Estadual Paulista. Botucatu. 166 pp.

Nogueira, G.C. and Bragagnolo, N. 2002. Assessment of methodology for the enzymatic assay of cholesterol in egg noodles. Food Chem, 79: 267-270.

Oliveira, R.M.; Osório, J.C.S.; Borba, M.F.S.; Osório, M.T.M.; Trindade, J.P.P.; Martins, L.S.; Lemes,
J.S.; Kessler, J.D.; Esteves, R.M.G. e Lehmen, R.I. 2012. Características in vivo e componentes corporais de cabritos naturalizado do alto Camaquã. Arch Zootec, 61: 43-54.

Osório, J.C.S. e Osório, M.T.M. 2005. Produção de carne ovina: Técnicas de avaliação in vivo e na carcaça. $2^{a}$ ed. Ed. Universitária. Universidade Federal de Pelotas. Pelotas. $82 \mathrm{pp}$.

Osório, J.C.S.; Osório, M.T.M.; Vargas Junior, F.M.; Fernandes, A.R.M.; Seno, L.O.; Ricardo, H.A.; Rossini, F.C. e Orrico Junior, M.A.P. 2012. Critérios para abate do animal e qualidade da carne. Rev Agrarian, 5: 433-443.

Perez, J.R.O.; Bressan, M.C.; Bragagnolo, N.; Prado, O.V.; Lemos, A.L.S.C. e Bonagurio, S. 2002. Efeito do peso ao abate de cordeiros Santa Inês e Bergamácia sobre o perfil de ácidos graxos, colesterol e propriedades químicas. Ciênc Tecnol Aliment, 22: 11-18.

Sainz, R.D. 1996. Qualidade das carcaças e da carne ovina e caprina. Reunião Anual da Sociedade Brasileira de Zootecnia, 32. Anais... Sociedade Brasileira de Zootecnia. Fortaleza. pp. 3-14.

Sañudo, C.; Campo, M.M.; Sierra, I.; María, G.A.; Olleta, J.L. and Santolaria, P. 1997. Breed effect on carcasses and meat quality of suckling lambs. Meat Sci, 46: 357-365.

SAS Institute Inc. 2001. SAS Users's Guide, Statistics. v. 8.2. SAS Institute Inc. Cary, NC. USA.

Silva Sobrinho, A.G.; Sañudo, C.; Osório, J.C.S.; Arribas, M.M.C.e Osório, M.T.M. 2008. Produção de carne ovina. Funep. Jaboticabal. 228 pp.

Todaro, M.; Carrao, A.; Barone, C.M.A.; Schinelli, R.; Occidente, M. and Giaccone, P. 2002. The influence of age at slaughter and litter size on some quality traits of kid meat. Small Ruminant Res, 44: 75-80.

Verde, L.S. 1996. Crescimento e crescimento compensatório na produção animal. UFSM. Santa Maria. 23 pp.

Zeola, N.M.B.L.; Silva Sobrinho, A.G.; Gonzaga Neto, S.; Marques, C.A.T. 2004. Composição centesimal da carne de cordeiros submetidos a dietas com diferentes teores de concentrado. Ciên Rural, 34: 253-257. 